\title{
Making the Nitrification Inhibitor with Latex- Chitosan Raw Material for Agricultural Fertilizers Products
}

\author{
Sudirman Habibie*, Moh Hamzah, Ade Sholeh Hidayat, Eryanti Kalembang, Jaudin, Diah Ayu Fitriani \\ ${ }^{*}$ Center for Material Technology, Agency for the Assessment and ApplicationTechnology Puspiptek Serpong Area, Tangerang Selatan, Banten
}

\begin{abstract}
Received: November 22, 2016; Accepted: December 15, 2016; Published: February 24, 2017
*Corresponding author: Sudirman Habibie, Center for Material Technology, Agency for the Assessment and ApplicationTechnology Puspiptek Serpong Area, Tangerang Selatan. Banten, Tel. no: +919914291115; E-mail: sudirmanhabibie@yahoo.com
\end{abstract}

\begin{abstract}
Fertilizer is one of the priorities for the agricultural industry and it contributes about 15 to $30 \%$ in the cost structure of rice farming. Capacity of national urea production in Indonesia is about 8 million tons per year while the needs are about 9 million tons per year. According to the Ministry of Industry in 2015 urea production can be increased by $6 \%$ from the previous national urea production capacity. On the use of fertilizers in the field, however, lost of nutrients during fertilization in the field (paddy) occurs a lot, so the efficiency of fertilizer use is reduced partly due to nitrification and urease. Therefore, it needs innovation and technological development of efficient agricultural fertilizer currently need to modify fertilizers with coating technology of nitrification inhibitor on the surface of the fertilizer granules. In this study the nature polymers (latex and chitosan) are used as a raw material nitrification inhibitors, several studies have shown that chitosan has a performance as anti bacteria that can be applied in agriculture. The study of a material generally involves the characterization by SEM and FT-IR to determine the characteristics micrographics and molecular bonding group of materials including latex-chitosan. The results of the study nitrification inhibitor made from latex-derived chitosan found that optimum formula of latex-chitosan mixture is sample with the mixture of latex $20 \%$ and chitosan $80 \%$ and be compatible with the surface of agricultural fertilizer granule, and a layer of latex-chitosan capable of strengthening the structure of fertilizer granules when tested in water for 3 months. This latex-chitosan based fertilizer shown as slow release fertilizer (urea and NPK) and resistant to moisture.
\end{abstract}

Keywords: Nitrification Inhibitor Fertilizer Products; Latex; Chitosan; Fertilizer Industry; SEM And FTIR

\section{Introduction}

NAWA CITA is a priority agenda of the Cabinet Working of Indonesia Government (2014-2019 Programs) directing agricultural development forward to achieve food sovereignty, so that Indonesian people can organize and fulfill its people with food independently, in terms of: food sufficiency from domestic production, regulate food policy independently, and to protect and make farmers prosperous as the main perpetrators of agri- food businesses [14]. The government continues to encourage the development of the fertilizer industry to achieve national food security program that is aligned with Nawa Cita Working Cabinet, which is to realize economic independence by moving the strategic sectors of the domestic economy.

Fertilizer is one of the priority industries for agriculture and it contributes 15 to $30 \%$ in the cost structure of rice farming business. National urea production capacity is about 8 million tons per year while its needs are about 9 million tonnes per year [4]. According to the Ministry of Industry in 2015, urea production can be increased by $6 \%$ of the national production capacity of urea from the operation of urea fertilizer factory PT [3].

On the use of fertilizers in the field is still a lot to lose nutrients during fertilization in the field (fields) so that the efficiency of fertilizer use is reduced partly due to nitrification. Nitrification is an activity of oxygen on ammonium ion $(\mathrm{NH}+)$ at a specified time by the bacteria Nitrosomonas in the soil. The bacteria transform ammonium ions into nitrite (NO2-), which subsequently changed again into nitrate (NO3-) by Nitrobacter and Nitrosolobus bacteria. Urease is an amide- $\mathrm{N}$ transformation of urea into ammonium hydroxide and ammonium influenced by process of urea hydrolysis in the soil. This process impacts the form of ammonia volatilization into the air [16].

The loss of $\mathrm{N}$ as nitrogen gas for denitrification, loss of $\mathrm{N}$ as ammonia gas due to volatilization and loss of $\mathrm{N}$ as nitrate because of washed (leaching) by flowing water. The cycle of decomposition of fertilizers can be seen in Figure 1 and 2. Nitrogen loss due to denitrification is estimated at $30-40 \%$, volatilization at $10-20 \%$, leaching ranges from $44 \%$ and because of erosion can reach $45 \%$ [18]. Given the above issues, farmers bear the loss of fertilizer costs due to the inefficiencies of fertilizer.

Modification fertilizers by coating with nitrification inhibitor of agri-fertilizer in commercial known as Slow Release Fertilizer (SRF) or Controlled Release Fertilizer (CRF). Technically nitrification and urease inhibitors are modified by means of 


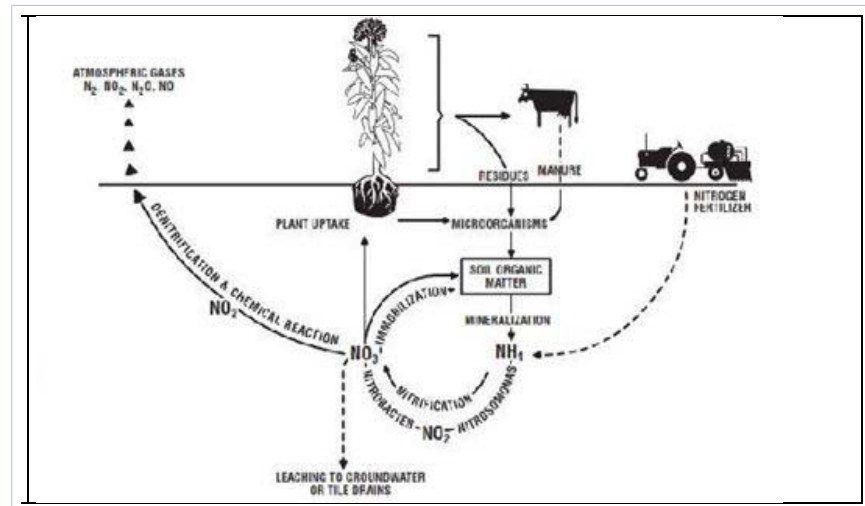

Figure 1: The cycle of decomposition of fertil izers and nitrification and aeration in the soil (Nelson and Huber)

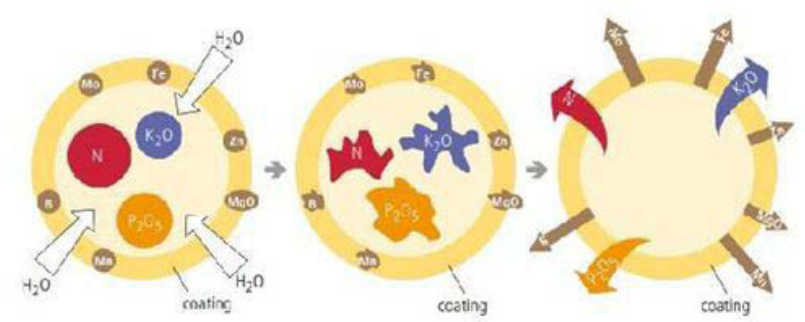

Figure 2: Process release fertilizer nutrients (Hähndel, BASF, 1997)

coating fertilizer with materials that react chemically, such as fertilizers ureaformaldehyde, it appears that the proportion of nitrogen contained can be released into the soil very slowly (or not at all). Meanwhile, if using polymer materials for long periods is losing its impact characteristics of soil cation exchange capability hindered because the polymer. The use of this material can lead to the accumulation of unwanted plastic residue (up to $50 \mathrm{~kg}$ per ha and year) [8].

Other materials made of starch is also used in the manufacture of urea slow-release in the form of granules using natural zeolites, where urea powder mixed with natural zeolite powder as a matrix and granulated using binder starch [7]. In conjunction with the release of urea coincide with hydrolysis process, in which it will weaken the bonds of starch binders due to water intrusion. The same process is carried out at production of a slow-release compound fertilizer using natural zeolite by blending NPK nutrients of urea, $\mathrm{KCl}, \mathrm{DAP}$, and Zeolite [7]. In commercial, the use of starch as a binder still can fluctuate its price, because it is part of the food raw materials.

Latex is a material which is dispersed liquid polymer, in which the particle size achieve sub-micron. Its characteristics capable of acting as technically latex adhesive materials can be used as agricultural fertilizers nitrification inhibitor coating because it has advantages; abundant materials, biodegradable, water-soluble that will facilitate the process of coating fertilizer, it can even be included such as fertilizer nutrients $(\mathrm{P}, \mathrm{K}, \mathrm{Mg}$, and others). Latex can be degraded due to exposure to UV rays.
Meanwhile there are few studies on the use of chitosan for use in agriculture. Chitin and its derivatives, chitosan, although not dissolved in water but can be decomposed by photodegradation as amine groups absorb UV light at which agricultural land is not irrigated [10]. Technical capability of chitin and its derivatives (chitosan) to agricultural applications among others; biocides (fungicides, bactericides, insecticides, and other), nitrogen fertilizer, biostimulant or growth regulators [12].

\section{Research Methodology}

\section{Materials Used}

Materials used in this study are fresh latex with Dry Content (DC) of $60 \%$ and chitosan derived from Biotech Surindo Indramayu. Acetic acid used to dissolve the chitosan was $1 \%$ acetic acid solution. The granules fertilizer to be used for applying coating on its surface was derived from 16-16-16 NPK fertilizer products of PT. Petrokimia Gresik.

\section{Formulation Latex-Chitosan}

First is to make liquid preparations of chitosan by dissolving chitosan in 1\% acetic acid solution. Dilution latex, meant to get latex dispersion corresponding to the formula mixture with chitosan. Mixing latex-chitosan applied by spray coating method then after dried latex-chitosan materials respectively calculated and simulated comparison of the percentage of latex-chitosan, so its mixture can be generated. Formula mixture of chitosan-latex can be seen in (Table 1).

\section{Characterization}

Micrographics observations of thin layer structure of latex-chitosan composite is applied to the surface of the fertilizer granules using Scanning Electron Microscopy (SEM) include coating thickness and pore. Observations using FTIR conducted to observe the types of functional groups of molecules that occur in mixing the latex and chitosan, FTIR used was brand Thermo Scientific Nicolet IS50 series. Both of these observations performed in the lab materials, Materials Technology Center, in the Serpong area.

\section{Latex-Chitosan Application for Coatings on Fertilizer Granules}

Liquid latex formula-chitosan was used as coating materials in the agricultural fertilizer products using spray methods, as shown in Figure 3.

\begin{tabular}{|c|c|}
\hline \multicolumn{2}{|c|}{ Table 1: Formula and mixture ratio of latex-chitosan } \\
\hline \multicolumn{2}{|c|}{ Mixture Ratio (\%) } \\
\hline Latex & Chitosan \\
\hline- & 100 \\
\hline 20 & 80 \\
\hline 30 & 70 \\
\hline 50 & 50 \\
\hline 60 & 40 \\
\hline 40 & 40 \\
\hline
\end{tabular}


After that the drying process in the oven is carried out to evaporate the water content of the latex-chitosan composite.

\section{Results and Discussion}

Prior to SEM and FTIR test, it needs to be made samples that corresponding to its characterization. Latex, chitosan and latexchitosan composite samples (Figure 4 and 5) form thin sheets dried in an oven. Characterization is also performed on samples of fertilizer granules after coating with latex-chitosan composite.

Observations using SEM to the chitosan coating obtained that chitosan particle agglomeration occurs to form pores, figure 6 . This may be due at the time of dissolution of chitosan in $1 \%$ acetic acid resulted in the formation of the fiber pattern agglomeration compared with SEM results from the initial chitosan. Latex layer has a pattern of parallel fiber lamella, figure 7 , while latex-chitosan layer patterned heterogeneous, figure 8. The image in Fig. 8 is one of the most interesting results of the SEM. The formation of C-S-H gel type I can be seen. The intertwining of reticulated C-S-H gel explains it has more secondary bonding distributed throughout the microstructure joining the portlandite particles and other hydrates. [1].

The test results characteristics with SEM method shows that the thickness of the layer of latex-chitosan granules on the surface of agricultural fertilizer products can be seen in Table 2. While measurement results of pore diameter latex-chitosan coating on the surface of the fertilizer granule products can be seen in (Table 3).

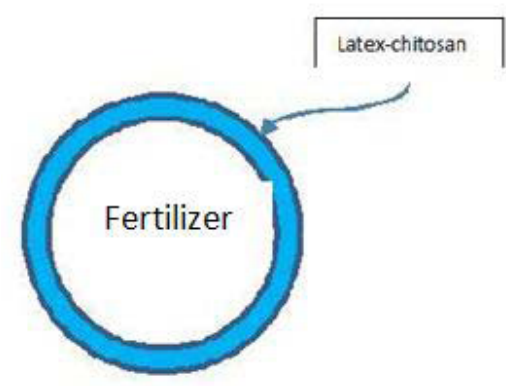

Figure 3: Description the layer of latex-chitosan

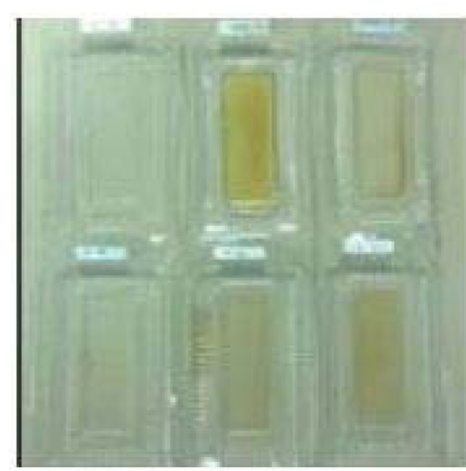

Figure 4: Samples thin layer of latex, latex-chitosan and chitosan

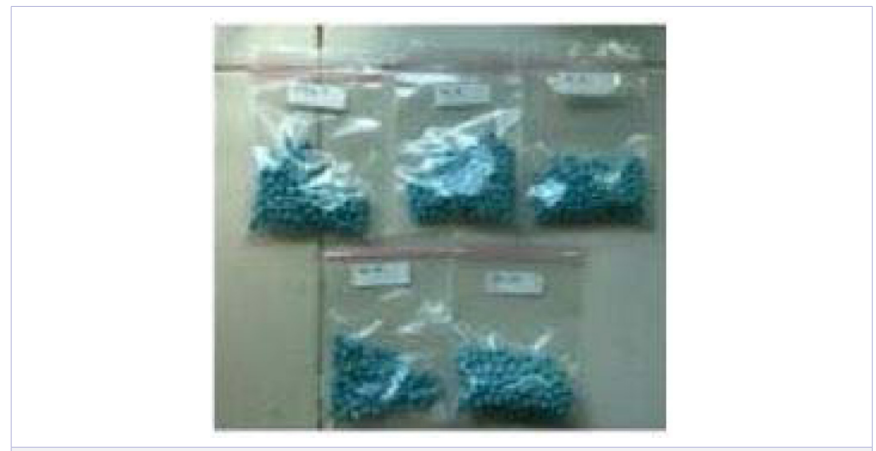

Figure 5: Results of Surface coating of fertilizer granules

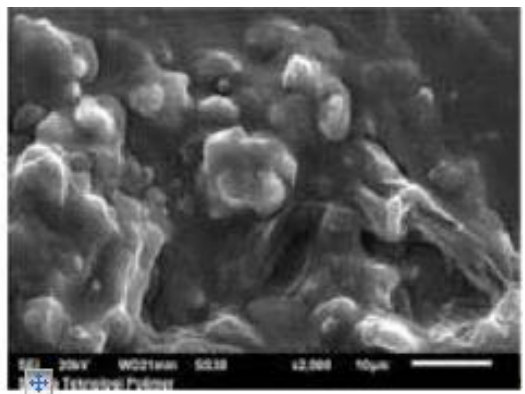

Figure 6: Patten micrograph of chitosan layer

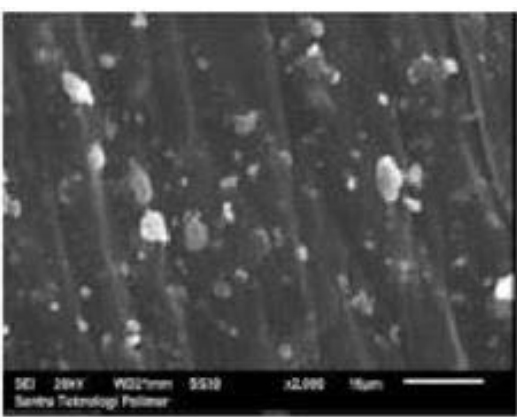

Figure 7: Pattern micrograph of latex layer

In observation using FTIR, (figure 9) done only on a sample of latex-chitosan composite formula of latex $60 \%$ and $40 \%$ chitosan. The observation of latex-chitosan composite shows the appearance of the spectrum with a peak at a wavelength as follows.

The principle of pure chitosan FTIR absorption peak was observed and is associated with the stretching vibration $-\mathrm{OH}$ group that overlaps with the stretching vibration of $\mathrm{N}-\mathrm{H}$ in the range of 3,750 to $3,000 \mathrm{~cm}-1$. Bending vibration of methylene group and methyl also seen in each of 1375 and $1426 \mathrm{~cm}-1$. Band spectrum in the range of 1.680 to $1.480 \mathrm{~cm}-1$ is identified with the vibration of the carbonyl bond of the amide groups and the vibration of the protonated amine groups. Vibration CO group is found in the range of 1,160 to $1,000 \mathrm{~cm}-1$. In addition, the spectrum band situated around $1150 \mathrm{~cm}-1$ was associated with asymmetric vibration of $\mathrm{CO}$ on oxygen bridge resulting from 
deacetylation of the chitosan. Finally, the spectrum a small peak at $\sim 890 \mathrm{~cm}-1$ relating to the movement of saccharides structure of chitosan[13]

Further details of the polymer functions groups were studied using ATR-FTIR analysis. Fig. 9 shows the main characteristic peaks of NR. It is at $3025 \mathrm{~cm}-1$ (= CH stretch), $2956 \mathrm{~cm}-1(\mathrm{CH}$ stretch of methyl group), $2915 \mathrm{~cm}-1$ (C-H stretching of methylene group), $1375 \mathrm{~cm}-1$ (CH stretch of methyl group), $1453 \mathrm{~cm}-1$ (CH stretch of methylene group), and at $835 \mathrm{~cm}-1$ ( $\mathrm{CH}$ wagging). The spectrum of chitosan film as shown in Fig. 9, there is no clear distinction between each film. However, when observations were made detail, $\mathrm{C}-\mathrm{O}-\mathrm{C}$ groups were affected. For incorporation of chitosan with NR, the peak at $1040 \mathrm{~cm}-1$ (C-O-C out-of-plane bend) increased greatly [15].

The next test is soaking granules of fertilizer that has been coated latex-chitosan composite is intended to meet the criteria of slow-release fertilizer that is resistant to the surface by the water pressure, and calculate the endurance time until breaking into pieces. These results may reveal the ability of latex-chitosan layer that coats the surface of the fertilizer granules. The result of immersion in water to fertilizer coated latex-chitosan composite against the resistance of the water showed after 3 months of immersion, latex-chitosan composite is still intact, while the immersion test applied on uncoated agricultural fertilizer NPK 16-16-16, the fertilizer destroyed in 5 seconds, see (Figure 10).

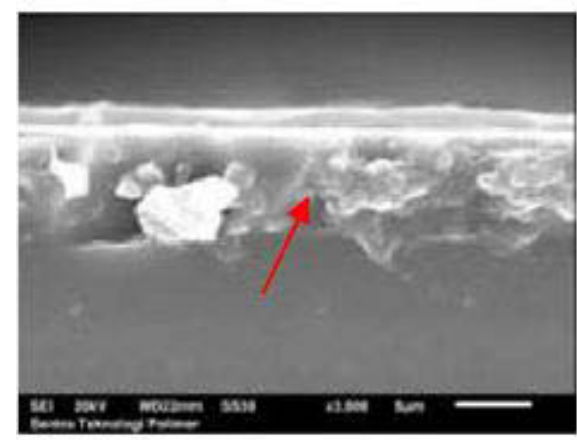

Figure 8: Pattern micrograph of latex-chitosan layer (20:80)

Table 2: The thickness of the layer of latex-chitosan coating on the surface of the fertilizer

\begin{tabular}{|c|c|c|}
\hline No & $\begin{array}{c}\text { Formula } \\
\text { latexchitosan }\end{array}$ & Thickness $(\boldsymbol{\mu m})$ \\
\hline 1. & $0: 100$ & 197.798 \\
\hline 2. & $60: 40$ & 180.710 \\
\hline 3. & $20: 80$ & 84.501 \\
\hline
\end{tabular}

Table 3: The pore diameter latex-chitosan coating on the surface of the fertilizer

\begin{tabular}{|c|c|c|}
\hline No. & Sample Name & The pore diameter \\
\hline 1. & $0: 100$ & 2.880 \\
\hline 2. & $60: 40$ & 0.960 \\
\hline 3. & $20: 80$ & 4.160 \\
\hline
\end{tabular}

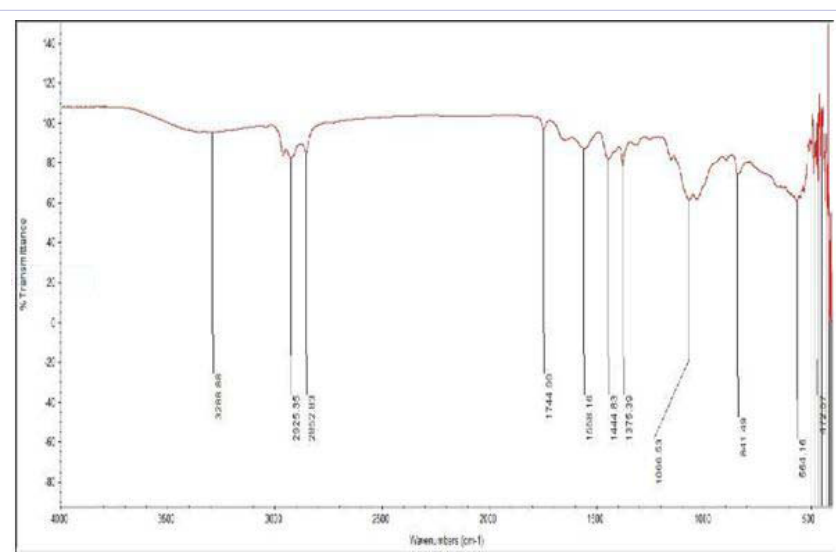

Figure 9: The test results of samples FTIR Latex-Chitosan composite $(60-40)$
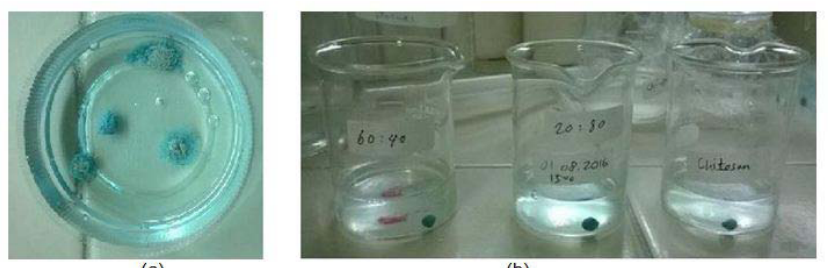

(a)

Figure 10: Immersion test of fertilizer granules (a) before and (b) after coating with latex-chitosan composite

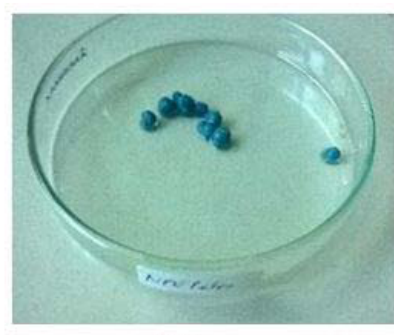

(a)

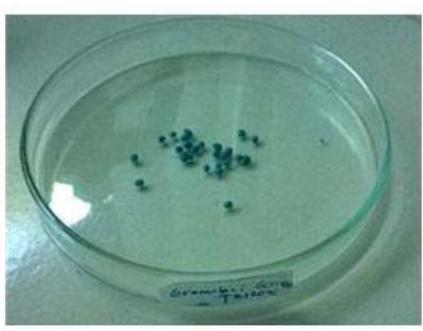

(b)
Figure 11: The moisture resistance test of (a) before and (b) after coating with latex-chitosan composite 40:60

According [9] that the fertilizer can be described as a slow release if the nutrient or nutrients declared as a slow release meets the conditions laid down, including at a temperature of 250C, which meet the following three criteria, namely: no more than $15 \%$ is released at 24 hours, not more than $75 \%$ released for 28 days and at least about $75 \%$ is released at the time of the release stated.

The physical characteristics of granule products of agricultural fertilizer NPK 16-16-16 is hygroscopic and can absorb water from the air which has humidity. This trait is a weakness in terms of handling the product during post-production such as storage (storage, bagging, and applications) and transportation of fertilizer. Therefore, the hygroscopic agricultural fertilizer conducted number of experiments by providing coating on fertilizer use latex-chitosan composite, coating is expected to 
protect agricultural fertilizer from the influence of air humidity but does not affect the function of the fertilizer, see (Figure 11).

\section{Conclusion}

Results of the research showed some conclusions as follows: latex-chitosan composite can be used as a coating material of agricultural fertilizer products with some formula such as chitosan without latex, latex-chitosan 20:80, latex-chitosan 60:40. Coating latex-chitosan in agricultural fertilizer products resulted in thicknesses varying between 84.50 - $197.7 \mu \mathrm{m}$ and a pore diameter of $2.88-4: 16 \mu \mathrm{m}$. Testing of immersion in water on agricultural fertilizer products coated with latex-chitosan is able to withstand water pressure at the surface for a long time about 3 months so that it supports the criteria of slow-release fertilizer. Latex-chitosan composite coating is also capable of protecting agricultural fertilizer from air humidity, so the fertilizer can be durable in storage.

\section{Acknowledgements}

The authors would like to thank to the Ministry of Research and Technology and Higher Education for funding this work through INSINAS program, and BPPT Engineering (BE) for administration and also Director of Center for Material Technology for supporting this program through the permission to use laboratory facilities as well as to all our colleagues in Center for Material Technology.

\section{References}

1. UT Bezerra, R.M Ferreira, J.P Castro-Gomes.The Effect of Latex and Chitosan Biopolymer on Concrete Properties and Performance. Key Engineering Materials. 2011;466:37-46.

2. Chairil Anwar. "Manajemen Dan Teknologi Budidaya Karet". 2006;Pusat Penelitian Karet, Medan, Indonesia.

3. Ellena, Pabrik. Pupuk Kaltim 5 Support Food Security National, Business Economics, Industry and Services, Regional News. 2015.

4. Fauzi A. Memperin: Government Continues Push Fertilizer Development ', News, Saturday, 03.28.2015.

5. Frye WW. Nitrification inhibition for nitrogen efficiency and environment protection. IFA International Workshop on EnhancedEfficiency Fertilizers, Frankfurt. International Fertilizer Industry Association, Paris, France. 2005
6. Hamza M, et al. Slow Release Fertilizer Urea granules In The Form Of The Use of Natural Zeolite and Process Pembuatannya, Certificate of Patent Patent Number: P0023827 ID, Ministry of Law and Human Rights, 2007.

7. Hamzah M, et al. Making Slow Release Fertilizer Using Natural Zeolite, Certificate of Patent Patent Number: P0027121 ID, Ministry of Justice and Human Rights, 2010.

8. Hähndel R. BASF Aktiengesellschaft (1997): Reply to the request on controlled-release fertilizers. Personalcommunication. In http:// www.uenf.br/Uenf/Downloads/ PRODVEGETAL_3434_1190664078. pdf

9. Kloth B. Aglukon Spezialdünger GmbH: Reply to the request on controlled - release fertilizers. Personal communication. In ControlledRelease and Stabilized Fertilizers in Agriculture (1997). 1996.

10. Mucha M, Pawlak A. Complex study on chitosan degradability. Polymery. 2002;47:7-8.

11. Nelson DW and Huber D. Nitrification Inhibitors for Corn Production. National Corn Handbook. USA.

12. Russell G Sharp. "A Review of the Applications of Chitin and Its Derivatives in Agriculture to Modify Plant-Microbial Interactions and Improve Crop Yields". Agronomy. 2013;3(4):757-793. doi:10.3390/ agronomy3040757

13. Silva SMLB, Carla RC, Fook MVL, Raposo CMO, Carvalho LH, Canedo EL. Application of infrared spectroscopy to analysis of chitosan/clay Nanocomposites. In: Theophanides T, editor. Infrared spectroscopy - materials science, engineering and technology. Croatia: InTech. 2012;43-62.

14. Sulaiman A. 'Rencana Strategis Kementerian Pertanian Tahun 2015 - 2019', Kementerian Pertanian, 2015.

15. Taweepreda W, Tuaybut S, Puangmanee S, Khoa TD, Preparation Of Positively Charged Membrane From Natural Rubber Latex Blending With Chitosan, Communications In Physics. 2014;24(3S1):51-56. doi:10.15625/0868-3166/24/3S1/5145

16. Trenkel ME, Controlled-Release and Stabilized Fertilizers in Agriculture, the International Fertilizer Industry Association Paris, December 1997.

17. Trenkel ME. Controlled-Release and Stabilized Fertilizers : An Option for Enhancing Nutrient Use Efficiency in Agriculture, the International Fertilizer Industry Association Paris, 2010.

18. Yoshida T, Padre BC, "Nitrification and Denitrification in Submerged Maahas Clay Soil", Soil Science. 1974. 